\title{
De la sociología de la crisis a la crisis de la sociología. XVIII Conferencias Aranguren
}

\section{From the sociology of crisis to the crisis of sociology. XVIII Aranguren Lectures}

\author{
IGNACIO SOTELO
}

Freie Universität, Berlin

Resumen. Crítica y crisis son los dos conceptos claves en el emerger de la sociología. El concepto de crisis que informa a la sociología en su primera etapa, en la que ésta termina por fundirse con la filosofía de la historia, desaparece en la reconstitución de la sociología que se lleva a cabo en vísperas de la Primera Guerra Mundial y que tiene en Max Weber a su representante más conspicuo. El empeño principal de este autor es superar la filosofía de la historia, eliminando cualquier residuo metafísico en la ciencia social.

La crisis de la sociología se evidencia en que, pese a los esfuerzos de los últimos decenios, no ha logrado una identidad ampliamente compartida por la comunidad científica de los que se llaman sociólogos, claramente divididos entre los que aspiran a una visión global de la sociedad y los que rechazan planteamientos generales y tratan de integrar los hechos recogidos en teorías de mediano alcance.

Palabras clave: Crítica, crisis, filosofía de la historia, sociología.
Abstract. Criticism and crisis are the key concepts in the emergence of sociology. The concept of crisis that shapes the beginning of sociology, when it fuses with philosophy of history, disappears during the reconstruction of sociology that takes place on the eve of World War One. It was the main purpose of Max Weber, its most outstanding representative, to overcome philosophy of history by removing any metaphysical residue in social science.

The crisis of sociology is shown in its failure in attaining an identity that could be broadly shared by the scientific community of sociologists, despite last decades efforts. Sociologists are clearly divided between those who aim at a global vision of society and those who reject general approaches and try to integrate collected facts into middle range theories.

Key words: Criticism, crisis, philosophy of history, sociology.

Como es bien sabido, Aranguren fue filósofo por formación y vocación. La religión primero, después la ética, fueron sus principales campos de reflexión, pero la arbitrariedad ministerial que unió en una misma cátedra la ética y la sociología le obligó a enseñar también esta disciplina, así que tuvo que introducirse en un área por la que había transitado poco. Reunió sus primeros 
ensayos sociológicos en el libro La juventud europea y otros ensayos (1961), que atestigua la estrecha relación que tuvo el profesor con la juventud universitaria, así como anunciaba en El erotismo y liberación de la mujer (1972) la que iba a ser la gran revolución de la sociedad española. Pero su mayor aporte a la sociología es sin duda La comunicación humana, libro aparecido en 1966 en inglés, y traducido a nueve lenguas, en el que a partir de la filosofía del lenguaje desemboca en la sociología de la comunicación.

Con la misma libertad ensayística que ejerció Aranguren, y como homenaje al maestro en el centenario de su nacimiento, me pregunto por la significación y alcance de la sociología en los dos últimos siglos. Ofrecer en un breve artículo una visión de conjunto a muchos les parecerá irrealizable, a algunos incluso un dislate. Y, en efecto, desde el interior de la disciplina el empeño no tendría mucho sentido; en cambio, si nos colocamos fuera, la tarea parece más factible, de la misma manera que desde el espacio cósmico alcanzamos una visión del planeta.

\section{La sociología, ciencia autónoma}

El sociólogo, empero, rechaza cualquier mirada metasociológica que trate de dar cuenta de lo social desde una dimensión histórica, económica, jurídica y, Dios nos libre, filosófica. Se entiende este resquemor, si tenemos presente los esfuerzos que la disciplina ha tenido que hacer para desprenderse, tanto de la filosofía como de la historia, sobre todo de la fusión de ambas en la filosofía de la historia. La sociología se erige en ciencia autónoma cuando reconoce, como escribió Emile Durkheim, que «la causa determinante de un hecho social hay que buscarla en los hechos sociales que la anteceden» ${ }^{1}$. Lo social se explica exclusivamente por lo social, es decir, dentro de los límites que enmarcan a esta ciencia. La sociología existe como ciencia autónoma porque tiene un campo que le es propio: «los hechos sociales». Si tardó hasta finales del siglo XIX el que la sociología lograse instalarse como ciencia autónoma, se comprende que, después de un siglo largo de tratar de independizarse, nada repudie tanto como una visión global que proceda de un enfoque exterior que le sea ajeno.

Resulta, sin embargo, harto sospechoso este afán de la sociología de presentarse como una ciencia autónoma, cuando observamos que las diferencias con las otras ciencias sociales, surgidas a la par, provienen más de los contenidos en los que cada una centra la atención - la economía se ocupa del manejo de recursos escasos, la historia, de lo ocurrido en el pasado, la ciencia política, de la organización del poder, la antropología, en el mundo anglosa-

1 Émile Durkheim, Les régles de la méthode sociologique, Alcan, Paris, 1895. Cap. V. Reglas relativas a la explicación de los hechos. 
jón, o la etnología en el alemán, estudia las sociedades «primitivas» más alejadas de la nuestra - que de los supuestos metodológicos, todas ellas ciencias empíricas que se basan en la recolección de hechos «relevantes», relevancia que, en última instancia, sustenta el armazón teórico que hayan logrado levantar. Pese a que la sociología era consciente «de que los "hechos sociales" están indisolublemente ligados entre sí y, sobre todo, que deben ser tratados como fenómenos naturales, regidos por leyes invariables, decir que las diversas ciencias sociales deberían ser ramas de la sociología es, por tanto, afirmar que deberían ser también positivas, que deberían desarrollarse dentro del mismo espíritu que las restantes ciencias de la naturaleza» ${ }^{2}$.

En el mare mágnum de las distintas ciencias sociales que emergen entre la segunda mitad del siglo XVIII y la primera del XIX, lo que en el fondo se pretende es una ciencia que se ocupe del hombre en sus diversas dimensiones. En los comienzos los saberes dedicados al conocimiento del ser humano se mezclan entre sí, y la economía tiene que ver con la moral - Adam Smith, el autor de Teoría de los sentimientos morales (1759), escribe La riqueza de las naciones (1776) - y la naciente sociología se confunde en parte con la ciencia de la historia que está emergiendo. La consolidación de los saberes en compartimentos estancos, a lo que tanto ha contribuido su integración en la enseñanza universitaria - dejo a un lado los desperfectos ocasionados por una noción tan dañina como la de asignatura-, ha terminado por eliminar una de las cuestiones esenciales que se planteó en los comienzos, la de una posible integración unitaria de las ciencias sociales.

En efecto, la sociología nace con la ambición de integrar a todas las demás ciencias sociales. El vocablo que inventa Augusto Comte ${ }^{3}$ incluye al conjunto de las ciencias sociales que se vinculan en una misma aspiración a constituir una ciencia empírica, que en sus métodos no se diferencie de las ciencias naturales. El primer fracaso del que hay que dejar constancia es que la sociología no haya logrado convertirse, tal como fue su aspiración originaria, en la ciencia que bajo su jurisdicción integrase a las demás ciencias sociales. Tras este revés, no tuvo otro remedio que reclamar para sí contenidos propios en torno a la pretendida especificidad de lo social. Cualquier interpretación de lo social que vaya más allá de lo social la pone en cuestión, como ciencia autónoma.

2 Émile Durkheim, Sociologie et sciences sociales, RP, vol. 55, 1903. En Steven Lukes, Émile Durkheim. Su vida y su obra. Centro de Investigaciones Sociológicas, Madrid, 1984, p. 394.

3 Auguste Comte utiliza por vez primera el término «sociología» en el tomo IV de Cours de philosophie positive, Paris, 1830. 


\section{La crisis en el origen de la sociología}

La sociología, como ciencia, antecede a su denominación y, aunque en sus orígenes dieciochescos puedan nombrarse distintos precursores - Montesquieu, Condorcet, Holbach-, el alto honor de ser el padre de la sociología corresponde a Claude-Henri de Saint-Simon (1760-1825). Demolido el «antiguo régimen» con la Revolución francesa, es preciso construir un nuevo orden social, para lo que se requiere a su vez un saber social nuevo. La premisa fundamental de que parte Saint-Simon, y con él la sociología en sus inicios, es que todo orden social se fundamenta en un sistema de ideas y, por consiguiente, los cambios que observamos en la sociedad provienen de nuevos paradigmas cognoscitivos. Si las instituciones no son más que ideas que se han plasmado en la realidad, no cabe instalar un régimen social distinto sin establecer antes un nuevo sistema filosófico. «Se debe considerar la publicación de la Enciclopedia la causa mayor que ha determinado la revolución, crisis terrible, pero saludable en sus resultados, porque ha proporcionado a la sociedad los medios para reorganizarse de manera mucho más ventajosa para el bien público que lo que había sido el régimen teológico y feudal» ${ }^{4}$. A las revoluciones sociales y políticas precede siempre una revolución en los conocimientos. En base al conocimiento que proporcionan los nuevos saberes, las ciencias físico-naturales, que fueron forjándose en los siglos XVII y XVIII, Saint-Simon propone construir una ciencia social nueva que llamó «fisiología social», encargada de organizar el nuevo orden social que sustituya al desplomado «antiguo régimen». Lo llamó «sociedad industrial» que sus discípulos rebautizaron, recurriendo a un neologismo que apareció poco después de su muerte, con el vocablo de «socialismo».

Para Saint-Simon, «hay dos clases de trabajo científico, uno consiste en reunir hechos, el otro en reflexionar sobre ellos, es decir, en perfeccionar las teorías» ${ }^{5}$. Existen épocas en las que, centrados en la búsqueda de nuevos hechos, prima la crítica de lo viejo, y otras de síntesis, en las que el empeño principal es incluirlos en una teoría coherente. En los tiempos de calma y equilibrio social, las teorías articulan y legitiman el orden social establecido; pero al cambiar las ideas básicas sobre el mundo y el hombre, llegan años de inestabilidad y malestar social crecientes que obligan a restaurar las instituciones de acuerdo con los nuevos saberes. Al ser los avances en el conocimiento científico los que perfeccionan las instituciones sociales, constituyen en definitiva el motor del progreso.

${ }^{4}$ Saint-Simon, Opinions littéraires, philosophiques et industrielles, Oeuvres choisies, Bruselas, 1859, 3 volúmenes, reimpreso por Georg Olms Verlag, Hildesheim y Nueva York, 1973, vol. III, p. 258. p. 58 .

5 Introduction aux travaux scientifiques de dix-neuviéme siècle. Oeuvres Choisies, vol. I, 
Crítica y crisis son los dos conceptos claves en el emerger de la sociología. La crítica de los conocimientos heredados hace que se tambaleen las instituciones establecidas y, para salir de la crisis que provoca este desfase de los conocimientos con las instituciones, es preciso remodelarlas de acuerdo con los nuevos conocimientos. «La filosofía del último siglo ha sido revolucionaria; la del siglo XIX tendrá que ser organizadora» ${ }^{6}$. Reorganizar los conocimientos para reorganizar la sociedad es el empeño principal de Saint-Simon. «No tengo más que una pasión, pacificar Europa, más que una idea, reorganizar la sociedad europea» ${ }^{7}$.

Ambos vocablos, crítica y crisis, se derivan del griego krinein, separar, distinguir, decidir. Crítico es el que sabe diferenciar lo que en realidad es diferente, y crisis es aquel estado en el que sólo cabe la disyuntiva de perecer o cambiar. Esta definición es fiel a su origen en la medicina hipocrática: crisis es aquella fase de la enfermedad en la que se decide si el organismo pueda aún dar un vuelco hacia la curación, o si ya no queda más que una agravación continua que acaba en la muerte. Como tantos otros términos griegos aplicados al mundo natural, cabe rastrear un significado jurídico-social anterior. En Tucídides el vocablo crisis aparece aún en este sentido jurídico originario (I, 31; II, 53; VI, 60); pero también ya en una nueva acepción bélica, momento en que se decide una batalla (I, 23), así como en la hipocrática en su célebre descripción de la peste en Atenas (II, 49-52).

No tengo noticia de que el término crisis aparezca en los historiadores latinos o medievales. Únicamente sobrevive vinculado a la medicina hipocrática que en el Renacimiento tuvo un espléndido resurgir. En el siglo XVIII, con lo que se ha dado en llamar la «crisis del antiguo régimen», la noción de crisis vuelve a difundirse en su significado histórico-social, extendiéndose en el XIX, siglo histórico por antonomasia, a cualquier realidad humana, desde las entidades más abstractas — «la sociedad global», «nuestro tiempo», «la civilización occidental»— a la más concreta, el individuo — crisis de identidad - incluyendo a todos los grupos e instituciones intermedias, crisis de un determinado club deportivo o crisis de un partido político. No hay realidad humana o institución social que no se haya puesto en conexión con el concepto de crisis. La crisis global de la que hoy tanto se habla se remonta como concepto a más de dos siglos. Desde la Revolución francesa cada generación europea ha tenido la sensación de pasar, tal como la diagnosticó Saint-Simon para su tiempo, por una crisis severa.

La sociología nace con la crisis que ocasiona el derrumbamiento del «antiguo régimen». El motor de sus desvelos es esclarecer esta «terrible crisis en la cual toda la sociedad europea se encuentra comprometida» ${ }^{8}$. En un texto

${ }^{6}$ De la réorganisatión de la société européenne, vol. II, p. 256.

7 Mémoire sur la science de l'homme (1815), vol. II, p. 166.

8 Oeuvres de Claude-Henri de Saint-Simon. Éditions Anthropos 6 volúmenes, Paris, 1966, I, p. 143. 
tardío de 1821, Saint-Simon escribe: «la crisis en la que se encuentra el cuerpo político desde hace 30 años tiene por causa fundamental el cambio total del sistema social que tiende a operarse hoy en día en las naciones más civilizadas, como resultado final de todas las modificaciones que el antiguo orden político ha sufrido sucesivamente hasta esta fecha. En términos más precisos, esta crisis consiste esencialmente en el paso de un sistema feudal y teológico a un sistema industrial y científico. Durará inevitablemente hasta que la formación del nuevo sistema no esté en plena actividad» ${ }^{9}$. Saint-Simon traza el programa de lo que va a ser la sociología en su primera fase: diagnóstico de la crisis y recomendaciones para superarla.

Europa se encuentra en la transición de un sistema feudal y teológico a uno industrial y científico. El sistema feudal se fundamenta en una teología que sirvió para legitimar la acumulación del medio principal de producción, la tierra, en manos de una clase dominante que se impone por la fuerza de las armas, permitiéndose llevar una vida de holganza. Frente a esta clase «parasitaria» de latifundistas, eclesiásticos y militares, surge otra, «productiva», que internaliza la ciencia como la ideología propia. La lucha entre la clase «parasitaria» y la «productiva», o como también las llama Saint-Simon, una clase «feudal» y otra «industrial», define la crisis que vive Europa y marca el camino para su solución, superar este dualismo, construyendo una sociedad sin clases en la que todos los «productores» se esfuercen solidariamente en el desarrollo de la ciencia como el instrumento idóneo para controlar la naturaleza y la sociedad ${ }^{10}$.

Las ciencias sociales surgen del intento de diagnosticar en teoría, y superar en la práctica, las crisis vividas. Con la consolidación de las distintas ciencias sociales - economía, sociología, antropología, psicología, politologíase han ido elaborando conceptos muy distintos de crisis. A la multiplicidad semántica del vocablo crisis en el lenguaje cotidiano, se une la elaboración particular de este concepto en las distintas ciencias sociales: el economista, al referirse a la crisis, entiende algo muy distinto del politólogo, cuando habla de crisis de gobierno o crisis del parlamento, o el sociólogo culturalista, de crisis de los valores.

9 Idem, V, p. 3.

10 Recuérdese la famosa parábola de Saint-Simon: Supongamos que Francia pierda súbitamente una parte de los físicos, los ingenieros, los banqueros, los obreros manuales, los comerciantes y los agricultores. Como estos hombres son la flor de la sociedad francesa, sin los cuales la nación no puede vivir, perecería en el momento en que los perdiera. Hagamos otra suposición. Admitamos que Francia conserve todos los industriales y hombres de ciencia que posee, pero que tenga la desgracia de perder en el mismo día al hermano del rey, al duque de Orleáns, a todos los ministros de Estado, los mariscales, los cardenales y diez mil propietarios entre los más poderosos que viven noblemente. Este accidente afligiría a los franceses, porque tienen buen corazón, pero la pérdida de treinta mil individuos, considerados los más importantes del Estado, sólo sentimentalmente les afligiría, pues no provocaría ningún mal a la sociedad. 


\section{Saint-Simon, padre de la sociología y del socialismo}

Las instituciones han de acomodarse a los conocimientos, y según éstos van cambiando, se producen nuevos desfases en un proceso que tiene su propia lógica, de la que Saint-Simon concluye la existencia de leyes objetivas en la marcha de las sociedades. Conocer las que actuaron en el pasado permite prever el futuro. «Todas las cosas que han ocurrido y todas las que ocurrirán forman una sola serie, de la que los primeros términos constituyen el pasado, y los últimos, el futuro. El estudio de la marcha seguida hasta hoy por el espíritu humano nos revelará los pasos útiles que quedan por dar en la carrera científica y en la ruta hacia la felicidad» ${ }^{11}$.

Hasta el siglo XV la teología tuvo la primacía; en el Renacimiento pasó a los autores profanos, griegos y latinos; en el siglo XVIII es clara ya la preeminencia de las ciencias físico-naturales; una ciencia positiva del hombre marcará la construcción de la sociedad futura. El desarrollo interdependiente de los conocimientos y de las instituciones culmina en una filosofía de la historia que, siguiendo las huellas de Sant-Simon, Comte formula en el conocido esquema de los tres estadios, el teológico, el metafísico y el positivo.

Una vez que se ha desplomado la creencia cristiana de «que el mundo ha sido creado para el hombre y que el hombre ha sido creado a imagen de Dios» ${ }^{12}$, se sabe que todos los seres, inertes o vivientes, incluidos los humanos, forman parte de una misma naturaleza, de modo que las ciencias del hombre han de aplicar el mismo método de observación y experimentación que emplean las ciencias naturales. «La fisiología, de la que la ciencia del hombre forma parte, habrá que tratarla con el método que se aplica a otras ciencias físicas» ${ }^{13}$. Las dos ciencias básicas que provienen de la Antigüedad son la astronomía, que con la ley de la gravedad ha refundado Newton, estableciendo el nuevo modelo de ciencia, y la medicina, el primer conocimiento científico del hombre y, por tanto, la fuente primigenia del saber científico de lo humano en sus diferentes dimensiones. En la Memoria sobre la ciencia del hombre (1815), los maestros a los que Saint-Simon se remite son todos médicos: Félix Vicq-d'Azyr (1748-1794), Pierre Jean Cabanis (1757-1808), François Xaver Bichat (1771-1802). Junto a haber puesto énfasis en el papel de las ideas en el cambio social, el mayor mérito de la filosofía positivista es haber integrado en las ciencias naturales a las del hombre.

La «físiología social» que en los comienzos propuso Saint-Simon encajaba en la economía política que los ingleses habían puesto en circulación, pero a partir de 1817 se aparta cada vez más del liberalismo económico, convencido de que el orden que se establezca, además de una ciencia social, precisa de

11 Mémoire sur la science de l'homme (1815). Oeuvres choisies, II, pp. 12-13.

12 Mémoire sur la Science de l'homme, vol. II, p. 40.

13 Idem, p. 14. 
una nueva moral. Fascinado «por el precepto divino de organizar la sociedad de manera que garantice a la clase más pobre la más rápida y la más completa mejoría de su existencia moral y física» ${ }^{14}$, centra todos los esfuerzos en mejorar tan pronto como fuese posible la existencia moral y material de la clase más numerosa. En su último libro, que no en vano lleva por título Nuevo Cristianismo, su pensamiento se encamina hacia el socialismo - un término que, como el de sociología, aparece también, después de su muerte- entendido, no ya como un ideal moral, sino como resultado de las leyes del desarrollo histórico.

Conviene retener que sociología y socialismo, las dos corrientes principales del pensamiento social del siglo XIX, en buena parte provienen de una filosofía, tan creativa y deslavazada, como la de Saint-Simon. Pronto se bifurcan, marchando cada una por sendas separadas. Con el desarrollo de la industria, que crea un proletariado enfrentado al propietario del capital, resulta insostenible la idea saint-simoniana de incluir a trabajadores y empresarios en una sola clase de «productores», enfrentada únicamente a la clase «parasitaria», máxime cuando la restauración borbónica había emparedado a la clase media entre la nobleza terrateniente y la nueva clase obrera, cuya mayor parte, sobre todo los sectores empresariales, se alia con la vieja aristocracia. Entre los discípulos de Saint-Simon la sociología se escinde del socialismo: Enfantin y Bazard, propicios a defender los intereses del pueblo llano, adoptan posiciones socialistas, mientras que Comte erige la sociología como la ciencia propia de la nueva burguesía.

\section{El saint-simoniano Marx}

Amigo del padre y vecino de la familia en Tréveris, mentor del Marx adolescente, y luego su suegro, siendo aún estudiante de bachillerato, el barón Ludwig von Westphalen le introdujo en la obra de Saint-Simon, lectura que dejó una huella indeleble. El saint-simoniano Marx trató también de fundar una ciencia social que enunciara leyes objetivas del desarrollo de las sociedades, no sólo independientes de las intenciones de los humanos, sino incluso determinantes de su conciencia, con el propósito práctico de conocer en qué dirección irían los cambios que llevarían a un nuevo orden social. El joven Marx escribe, siguiendo a Saint-Simon, que «la ciencia natural será un día la ciencia del hombre, así como la ciencia del hombre se subsumirá en la de la naturaleza. Ambas formarán una sola ciencia» ${ }^{15}$. Leyes sociales objetivas marcan el desarrollo de las sociedades, pero también la conciencia y voluntad de los

14 Nouveau christianisme, Oeuvres choisies, vol. III, p. 323.

15 Karl Marx, Ökonomische-philosophische Manuskripte (1844). Tercer Manuscrito. En Frühe Schriften, vol. 1, Cotta-Verlag, Stuttgart, 1962, p. 604. 
individuos, que piensan y quieren moldeados por el contexto social en que se desenvuelven. Pero rechazó con la mayor contundencia que esta ciencia social pudiera ser la «físiología» que propuso el aristócrata francés y que luego, como sociología, difundió su discípulo, Auguste Comte, por quien Marx no sintió la menor simpatía.

En la segunda mitad del siglo XIX, para dar cuenta de la sociedad había que elegir entre la sociología que, constituida en ciencia social autónoma, trata de explicarla constreñida a lo social, y la ciencia social que propone Marx que abarca la totalidad del proceso histórico. La historia, que necesita recurrir a lo económico, lo social, lo jurídico, lo político y lo ideológico para hacerse cargo del pasado, es la ciencia social integradora de las demás ciencias sociales. Reducir, como hizo la sociología, lo social a una ciencia particular impide su conocimiento, ya que sólo resulta cognoscible en sus relaciones con las demás estructuras, económicas, políticas, jurídicas, ideológicas. La historia, al poner en relación las distintas dimensiones de lo humano, es la ciencia social unitaria que reúne al conjunto de las ciencias sociales. Únicamente la historia permite aprender estas «totalidades» en sus relaciones mutuas, mientras que el conocimiento se fosiliza, si se construyen artificialmente compartimientos estancos - economía, sociedad, política, cultura - cada uno promoviendo una ciencia particular que pretende bastarse a sí misma. Marx propugna una visión «total» de la historia, negándose a diferenciar distintas secciones autónomas - lo cultural, lo político, lo social, lo económico - como si cada una pudiera estudiarse por sí misma.

En consecuencia, Marx impugna de la manera más contundente la sociología, entendida como ciencia autónoma de lo social, a la vez que pretende constituir una ciencia social integradora, que cabe llamar también sociología en el sentido más amplio. Hasta la I Guerra Mundial marxismo y sociología compiten, como dos corrientes enfrentadas de una misma ciencia social. Tras la revolución rusa, el marxismo se anquilosa en una cosmovisión filosófica, el famoso «materialismo dialéctico», que trata de unificar las ciencias sociales y naturales. Acabada la II Guerra Mundial aparece una sedicente «sociología marxista», que si bien tuvo la virtud de poner de manifiesto los vínculos ocultos entre los dos sistemas en competición, parece, sin embargo, una contradicción en los términos: si la sociología es una ciencia de lo social que lo explica a partir de lo social, en ningún caso puede ser marxista, que supone la imbricación de lo económico, lo social, lo político y lo ideológico, en una «totalidad dialéctica».

Para Saint-Simon la causa primera de la crisis estaba en la disolución crítica de la filosofía que hasta entonces había sustentado el edificio social y, por tanto, superarla exigía la elaboración de una filosofía nueva que diseñara el orden social que era menester construir. Un Marx también convencido de la existencia de leyes objetivas en el desarrollo de las sociedades denuncia, sin embargo, el «idealismo histórico» que eleva las ideas a motor de la historia y 
a los científicos a sus verdaderos héroes. Rechaza que las ideas por sí solas impongan los cambios sociales e insiste en que son los modos de producir los que, en último término, modifican ideas y conocimientos. El «capitalismo», como Marx llama a la «sociedad industrial» de Saint-Simon, no necesita de una nueva filosofía sobre la que levantar una ciencia social «constructiva», sino que parte de una «economía política» que muestra la interrelación existente entre el desarrollo de las fuerzas productivas - recursos y tecnologíay las relaciones de producción, que incluyen las estructuras sociales que configura la propiedad privada de los bienes de producción, así como mentalidades, ideologías y demás «superestructuras» que de aquella se derivan. Hasta la I Guerra Mundial el marxismo se consideró la ciencia social unitaria, que integra a las demás ciencias sociales, en conexión con la ciencia natural, y que compite con una sociología, limitada a dar cuenta de lo social por lo social, que se esfuerza en afirmar su autonomía hasta el punto de terminar separándose de las ciencias naturales.

Hay que dejar constancia de una segunda diferencia fundamental con Marx. En Saint-Simon el conflicto se da entre los que trabajan y los que no trabajan de manera productiva, de modo que las dos clases en litigio son la «parasitaria» y la «productora». Eliminada la clase «parasitaria», en perfecta armonía los «productores» conseguirán un bienestar generalizado, al poner el saber científico al servicio de la producción. Marx, en cambio, subraya que en la sociedad capitalista la contradicción principal es la de capital-trabajo. Los dueños del capital están enfrentados a la fuerza de trabajo, las dos clases antagónicas que Saint-Simon incluía en la de «los productores».

Desde una visión global de la historia Marx también enfoca la crisis que vive la sociedad contemporánea como un fenómeno propio de la transición de un orden social a otro, pero piensa que únicamente cabe aprehenderla desde una concepción «materialista», es decir, desde su raíz económica. Para el «materialismo histórico» comprender la «crisis política» exige haber detectado previamente la «crisis social» que la provoca, a su vez indescifrable sin un análisis de la «crisis económica» que caracteriza al nuevo modo de producción capitalista.

Marx introdujo el concepto de crisis en la economía política. Frente a la economía clásica que postulaba un ajuste automático entre producción y demanda, señaló la sobreproducción en el origen de las crisis. El afán de beneficio lleva a aumentar la producción hasta mucho más allá de la capacidad de compra, no de consumo, con lo que se hace patente la paradoja del capitalismo de que resulten invendibles mercancías y servicios de que carecen una buena parte de la población. Aunque Marx no llegó a confeccionar una teoría acabada de la crisis económica, en su correspondencia encontramos observaciones abundantes, tanto sobre las crisis vividas, como las que vaticinaba y luego no acababan de fraguar, llegando al convencimiento de que, inherentes 
al modo de producción capitalista, serían cada vez más frecuentes y de mayor calado hasta terminar por derribarlo.

La socialdemocracia del último tercio del siglo XIX, convencida de que la revolución proletaria llegaría irremisiblemente empujada por las contradicciones internas del capitalismo, pudo instalarse cómodamente a la espera de que la próxima crisis fuese la definitiva. Marx acertó en vincular las crisis periódicas al modo de producción capitalista, pero desde el supuesto de un descenso continuo del beneficio del capital no pudo prever que, en vez de favorecer el derrumbe del sistema, a menudo las crisis lo fortalecen, al desembocar en un nuevo período de crecimiento económico. Después de las muchas y graves crisis vividas, a finales del XIX los países capitalistas pioneros eran mucho más ricos, permitiéndose incluso un aumento sustancial de los salarios que desmentía el pronóstico de la pauperización progresiva del proletariado, como factor decisivo del irremediable desplome del capitalismo. Al no desmoronarse, todo lo contrario, al robustecerse, terminó por imponerse en la socialdemocracia alemana el «revisionismo» de un Bernstein, ya plenamente convencido de que si la clase obrera lograra integrarse en un Estado democrático - a fin de cuentas, éste es el factor que hacía obsoleta la revolución- podría también beneficiarse de la inmensa capacidad de crecimiento que despliega el capitalismo.

\section{Evolución y sociología}

A diferencia de Francia, donde muy pronto sociología y socialismo surgieron a la par en el saint-simonismo, y de Alemania, donde el hegelianismo promovió una nueva ciencia social que algunas de sus ramas, no sólo el marxismo, conectaron con el socialismo, en Gran Bretaña, sociología y socialismo echaron raíces con considerable retraso. El utilitarismo, por un lado, y la nueva ciencia económica, por otro, proporcionaban suficiente apoyo ideológico a las clases medias ascendentes. En el país originario de la «revolución industrial», en el que el proletariado crecía rápidamente, se hacía muy arriesgado para la nueva clase empresarial desprenderse de la alianza con la nobleza, en la que el gobierno parlamentario se apoyaba desde la «revolución gloriosa».

Se comprende que en una sociedad en que las instituciones burguesas se sentían definitivamente asentadas desaparezca la angustia de las crisis y el afán de renovación se detecte únicamente en los sectores sociales menos favorecidos. La sociología proveniente del positivismo francés no pudo ejercer en Gran Bretaña el ímpetu reformador, abierto al futuro, que caracterizó a su aparición continental. Arriba a Inglaterra por un conducto marginal, Herbert Spencer (1820-1903), publicista autodidacto, sin apoyos institucionales, que llegó a ser el sociólogo de mayor popularidad e influencia de la época victoriana. Despojada ya de su pathos reformista el pensador inglés inserta la so- 
ciología, al igual que su maestro Comte, en un sistema universal de las ciencias. Si en Comte los dos conceptos básicos de la sociología, estática y dinámica, provienen de la física, la primera estudia la estabilidad social y la segunda el cambio social, Spencer se nutre de la biología, la nueva ciencia natural que con el concepto de evolución surge en el siglo XIX. Spencer concibe a la sociedad como un «organismo» que se regula a sí mismo y que, como todos los demás, ha evolucionado hasta su actual estadio. Las sociedades son también producto de la evolución del universo, «de una homogeneidad indeterminada y sin conexión a una heterogeneidad determinada y conexa».

Este cambio de perspectiva, de la física a la biología, de Newton a Darwin, fortalece aún más la tendencia conservadora de la sociología. De las dos vertientes que tuvo la comtiana, estabilidad y cambio, «orden y progreso», Spencer elimina la segunda. Si el progreso social es tan seguro como lo es el crecimiento en la biología, resultará superfluo cualquier empeño reformista, y menos revolucionario; los cambios necesarios llegarán en el momento oportuno y de la forma adecuada. Si a ello se añade que Spencer corrige la sociología comtiana, en el sentido de que no es la humanidad, sino el individuo, el verdadero sujeto de la historia, el individualismo más agresivo toma cuerpo en la obra de Spencer, justificando «la lucha de todos contra todos» del primer capitalismo industrial (darwinismo social). La sociología remacha así su función ideológica, justificadora del orden existente, desempeñando un papel análogo al que en el «antiguo régimen» Saint-Simon otorgó a la teología.

Muy significativamente Spencer reduce a dos los tres estadios comtianos: la sociedad militar en la que predominan las relaciones de fuerza y de coerción, y la sociedad industrial, basada en la cooperación libre según el principio de la división del trabajo en la que descuellan el ingeniero y el industrial. El binomio sociedad militar y sociedad industrial, reformulado en sociedad tradicional y sociedad moderna, permanece incólume hasta nuestros días. La sociedad moderna se identifica con la sociedad capitalista, plenamente desarrollada, y tal como existe en el presente representaría la última etapa de la evolución histórica. El tema central de la sociología ya no es diagnosticar y contribuir a superar las crisis, sino estudiar en teoría, y apoyar en la práctica, la «modernización» de las sociedades que aún no hubieran alcanzado la etapa superior.

La influencia de Spencer fue decisiva en la consolidación académica de la sociología, pero no en el Reino Unido, donde su enorme éxito como publicista no facilitó el que penetrara en las universidades británicas, demasiado apegadas a la tradición humanista para acoger una ciencia social integrada en las ciencias naturales, sino en Estados Unidos, terreno especialmente abonado para su recepción. Tanto Lester F. Ward (1841-1913) como William G. Summer (1840-1910), pioneros de la sociología en el nuevo mundo, partieron de los Principios de Spencer ${ }^{16}$, pero con la tendencia a corregir su biologismo

16 The Principles of Sociology, 3 vols. Williams and Norgate, Londres, 1882-1898. 
absorbente, recalcando la importancia de los factores psicológicos individuales. También América Latina se mostró muy receptiva de la obra de Comte y Spencer. En 1882, la universidad de Bogotá inaugura la primera cátedra de sociología del mundo.

\section{El segundo nacimiento de la sociología}

«Spencer está muerto. Pero ¿quién lo mató y cómo? Éste es el problema» ${ }^{17}$. Todos los sociólogos, por lo menos los de mi generación, recuerdan las palabras con las que comienza La estructura de la acción social (1937). Talcott Parsons (1902-1979) rompe con el biologismo evolutivo, cuando la gran depresión ya había aniquilado por completo el optimismo que propagaba Spencer sobre la estabilidad del orden social establecido y el marxismo empezaba a penetrar en algunas universidades norteamericanas. En su estancia en Europa — primero en la London School of Economics, 1924-1925, luego en Heidelberg, 1925-1927- el joven Parsons se había familiarizado con la sociología europea de los dos últimos decenios que precedieron a la I Guerra Mundial. Debidamente adaptados a las necesidades y modalidades de Estados Unidos, en su primer libro Parsons importa el pensamiento sociológico de Vilfredo Pareto (1848-1923), Emile Durkheim (1858-1917) y Max Weber (1864-1920), los protagonistas de lo que muy bien cabría llamar el «segundo nacimiento de la sociología». A los tres une un mismo empeño en ofrecer un paradigma sociológico más efectivo que el positivista comtiano para contener un marxismo en rápida expansión.

En efecto, la sociología sufre una profunda transformación, cuando a finales del siglo XIX deja de proponer, como sujeto colectivo, hipóstasis abstractas del tipo de «la humanidad», «la sociedad», «la clase social», y pasa a ocuparse de los hechos sociales (Émile Durkheim) o de la acción social (Max Weber). En Durkheim esta ruptura se incluye todavía en la tradición positivista francesa que pretende establecer leyes objetivas en la sociología, del tipo que conocen las ciencias naturales. En este afán de objetivación Durkheim trata a los hechos sociales como cosas, que se caracterizan, tanto por pertenecer al mundo exterior, si se quiere forman parte de la naturaleza, como por imponerse coercitivamente. Entre los hechos sociales se ha de incluir la conducta humana, que también viene configurada por «hechos objetivos», que lo son, porque tampoco los podemos cambiar a nuestro antojo. «Una ciencia es un estudio que se ocupa de una porción determinada de lo real que trata de conocer y, si es posible, de comprender. Describir y explicar lo que es y lo que ha sido, es su única tarea, pero no le atañen las especulaciones sobre el

17 Talcott Parsons, The Structure of social Action, McGraw-Hill Book, 1937, The Free Press of Glencoe, Nueva York, 1949, Segunda reimpresión 1961, p. 3. 
futuro, aunque su último objetivo sea hacerlas posibles» ${ }^{18}$. Éste es el pequeño resquicio que deja para una acción política empeñada en el cambio. La sociología sólo tiene que ver con el presente, y se ocupa del pasado en tanto que contraste esclarecedor de lo que ha terminado por ser. Y ello porque presente y pasado son las dos únicas dimensiones temporales que pueden aprehenderse empíricamente. Al reclamar la sociología el status de ciencia, el futuro que no forma parte de lo real, es decir, de lo aprehensible empíricamente, deja de ser de su incumbencia, y no queda otro remedio que desenganchar la sociología del socialismo.

Durkheim se remonta incluso a un lejano pasado - la sociología conecta con la antropología - que se habría caracterizado por una solidaridad que llama mecánica, mientras que domina el presente una solidaridad orgánica que conlleva un grado mayor de interdependencia. La primera es propia de poblaciones escasas, organizadas en clanes, mientras que la segunda, basada en la división del trabajo, no sólo permite grandes aglomeraciones, sino que muestra una fuerte conexión entre sus miembros, lo que deja un espacio mayor para la iniciativa individual. Marx, en cambio, de la división del trabajo había derivado una sociedad enfrentada en clases antagónicas. Distinguir solidaridad mecánica de solidaridad orgánica sirve para diferenciar el pasado del presente, la misma función que en Spencer desempeña el binomio sociedad militar y sociedad industrial, y que con este mismo fin se mantiene hasta nuestros días en el de sociedad tradicional y sociedad moderna.

A diferencia de los sociólogos de la primera fase fundacional, Durkheim se remonta a un pasado muy lejano para entender el presente, a la vez que elimina el futuro, al que la ciencia no podría tener acceso por no ser una realidad tangible. En una sociedad en la que el orden establecido se considera ya definitivo en sus rasgos básicos, no tiene demasiado sentido ocuparse del futuro. Se cae entonces en la cuenta de que esta categoría resulta incompatible con una ciencia empírica, justamente lo contrario de lo que había pensado Saint-Simon, defensor también de una ciencia empírica, pero convencido de que a partir de las leyes objetivas que se comprueban en el pasado y se hacen inteligibles en el presente, cabría deducir a grandes rasgos lo que ocurrirá en el futuro.

Max Weber, en cambio, sí lleva a cabo una verdadera ruptura con la concepción positivista de la sociología, tanto en los contenidos, como en los métodos. Respecto a los primeros, introduce la de «acción social» como categoría central. Se actúa para conseguir un fin, la acción supone un objetivo, una finalidad, de modo que implica siempre una relación de medios a fines. «Toda reflexión sobre los últimos elementos del hacer humano, por lo pronto se vincula a las categorías de fin y medio» ${ }^{19}$. La sociología precisa de un sta-

18 Émile Durkheim, Le socialisme, Presses Universitaires de France, Paris, 1992, p. 35.

19 Max Weber, Die Objektivität sozialwissenschaftlicher und sozialpolitischer Erkenntnis (1902), Gesammelte Aufsätze zur Wissenschaftslehre, Tercera Edición, Mohr-Siebeck, Tubinga, 1968, p. 149. 
tus propio, ya que, a diferencia de las ciencias naturales en las que únicamente importa el porqué, en las ciencias sociales es imprescindible preguntarse por el para qué, por la finalidad de la acción. Y en cuanto a los métodos, éstos han de tener muy presente que no se llega directamente a la «realidad social», sino que es preciso «construirla» a partir de los datos empíricos a los que se tiene acceso («tipo ideal»). La acción social además de explicarse, poniendo de manifiesto sus causas, ha de comprenderse, revelando la finalidad buscada. Si en las ciencias naturales se ha eliminado la dimensión teleológica, en las ciencias sociales es la fundamental.

Weber se halla inmerso en la polémica de la Alemania de su tiempo sobre la peculiaridad de las ciencias sociales respecto a las naturales. Wilhelm Dilthey propuso «la vida» como realidad primaria — «realidad radical» la llamó Ortega - cuya intelección precisa incluirla en la dimensión histórica que le es propia: la vida se hace, es historia. De ahí que haya que separar las ciencias que se ocupan de la realidad histórico-social de las ciencias naturales, ya que las primeras «sólo puede explicarse y fundamentarse definitivamente en la obra misma» ${ }^{20}$. Lo social-cultural únicamente se entiende, si desde su interior se interpreta su significado, es decir, la hermenéutica es el método propio de estas ciencias que Dilthey llamó «ciencias del espíritu». Heinrich Rickert, cuyo pensamiento tuvo Weber muy en cuenta ${ }^{21}$, considera la hermenéutica exclusiva de los saberes humanísticos y recupera la dimensión empírica para las ciencias sociales, aunque éstas también hay que separarlas de las ciencias naturales. En el último tercio del siglo XIX, se perfilan tres saberes en Alemania, las ciencias humanísticas, las ciencias sociales y las ciencias naturales, y cada una exige su propia autonomía. Tres «culturas» que hasta bien avanzada la segunda mitad del siglo XX han permanecido cada una por su lado, sin apenas conexión ${ }^{22}$.

El pensamiento sociológico de Max Weber surge de la trifulca que mantienen las ciencias sociales con un positivismo residual. Su principal empeño es superar la filosofía de la historia, eliminando en la ciencia social cualquier poso metafísico. Para ello suprime, tanto el «sujeto totalizador» — «la sociedad», «la nación», «la raza», «la clase»— como cualquier otro vestigio historicista, expulsando nociones como «desarrollo» o «evolución». Pretende una ciencia social antihistoricista, yo diría incluso ahistórica, en la que se ha cercenado la dimensión temporal, y con ella el conflicto y el cambio.

Este afán de «objetividad» atemporal lleva a eliminar por completo la dimensión del futuro. Weber percibe en el presente una «burocratización»,

20 Wilhelm Disthey, Introducción a las Ciencias del Espiritu, Revista de Occidente, Madrid, 1956, p. 13.

21 Peter-Ulrich Merz, Max Weber und Heinrich Rickert, Die erkenntniskritischen Grundlagen der verstehenden Soziologie, Königshausen und Neumann, Würzburg, 1990.

22 Wolf Lepenies, Die Drei Kulturen, Soziologie zwischen Literatur und Wissenschaft, Hanser, Múnich, 1985. 
que ha de seguir caracterizando al futuro previsible, en cuanto es inherente, tanto al capitalismo tardío, como al socialismo, una alternativa que se revela sólo aparente. En cuanto supone una concepción temporal, procesual y en definitiva histórica de lo social, se comprende que en las más de mil páginas de Economía y Sociedad no aparezca ni una vez el término de «crisis» ${ }^{23}$. Pero por grande que haya sido el esfuerzo de Weber por eliminar la dimensión histórica de las ciencias sociales, en el binomio «sociedad tradicional-modernidad» el pasado se cuela de nuevo, y permanece en nuestros días en las sociologías que captan la sociedad desde una visión global de su desarrollo.

A la búsqueda de una ciencia social que se fundamente a sí misma, Weber se desprende tanto del positivismo cientificista de un Comte o de un Spencer, como se esmera en limpiar la ciencia social de las últimas reminiscencias histórico-filosóficas. Esto le lleva a enfrentarse a la filosofía de la historia implícita en el marxismo, que había adquirido especial vigor y prestigio con la rapidísima expansión de la socialdemocracia a finales del XIX. No cabe duda que la mejor manera de entender el pensamiento de Weber es interpretándolo como un diálogo de aceptación y de rechazo con Marx. Cuando en los medios obreros el revisionismo de Bernstein planteaba la entonces tan debatida «cuestión del fin del capitalismo», en el mundo académico Weber y Sombart fijaron la mirada en los comienzos para desentrañar su significado. Esta vuelta a los orígenes permite a Weber poner en tela de juicio la dialéctica de «base económica» y «superestructura ideológica» que tan alegremente manejaba el marxismo de la II Internacional.

Campeaba por el ambiente la idea de que la reforma protestante de alguna manera habría tenido que ver con el surgir del capitalismo, pero, ¿cómo explicar una relación, aunque no fuese de causa a efecto, sino de «parentesco», como la llama Weber, entre una determinada religiosidad, que pertenece a lo más íntimo de la personalidad, y una formación socio-económica como es el capitalismo? Al plantear esta cuestión en La ética protestante y el espíritu del capitalismo - un clásico de la literatura sociológica que en su tiempo, y hasta nuestros días, ha sido y es muy discutido- Weber inaugura un nuevo paradigma en la sociología con las siguientes tres aportaciones: 1. Muestra la autonomía de las creencias personales, incluida la dimensión ideológica, de las estructuras socioeconómicas. El ámbito de las ideas y creencias es independiente de las constelaciones socioeconómicas. 2. Cuando la ilustración parecía haber eliminado definitivamente la dimensión religiosa de la existencia, Weber subraya su papel fundamental en la configuración del mundo moderno. La sociología de la religión va a ser así una de sus grandes contribuciones a la sociología. 3. El ensayo deja patente la polisemia del vocablo

23 José M. González, buen conocedor de la obra de Weber, me corrige, todo lo más una o dos veces. 
«racional», con lo que rompe con el racionalismo del primer pensamiento ilustrado que estuvo en los orígenes de la sociología.

Sombart había definido el capitalismo como «el comportamiento económico racional». Definición que acepta Weber, sólo si previamente se precisa qué quiere decir racional. Lo racional consiste en que los medios se acoplen a los fines, un medio es racional, si sirve al fin que se propone. Para entender la racionalidad del capitalismo es preciso introducir una nueva categoría que se ha malentendido a menudo, la de «espíritu del capitalismo», que no hace mención en ningún caso a la esencia o naturaleza última del capitalismo, sino que tiene que ver sólo con el hecho de que todas sus acciones se encaminen a un único fin. El «espíritu del capitalismo» se muestra en que concentra todos los medios en la obtención de un único fin, la acumulación ilimitada, la acumulación por la acumulación, la acumulación como fin en sí mismo. El capitalismo es racional porque fija un único fin, la acumulación por la acumulación, como fin en sí mismo. Importa tener muy presente que en La ética protestante y el espíritu del capitalismo Weber no se ocupa de los orígenes del capitalismo, sino de los orígenes del «espíritu del capitalismo». Lo que Weber pone en conexión no es el capitalismo con el protestantismo, una hipótesis que fácilmente cabría desmontar como falsa, sino «el espíritu del capitalismo», es decir, el principio de acumulación infinita, con la ética protestante.

Cierto que encaminar todas las acciones a un solo fin racionaliza la conducta, pero ¿es acaso racional ese fin de acumulación infinita? Parecerá poco razonable en cuanto concibamos otros fines como, por ejemplo, el más obvio, satisfacer las necesidades humanas. El que se haya impuesto algo que parece tan poco razonable, como es la acumulación como único fin, lo explica Weber desde una determinada teología del calvinismo. La doctrina de la predestinación deja únicamente un resquicio para saber si se pertenece a los elegidos, y es que una vida ascética de renuncia y de trabajo tenga su compensación ya en esta vida.

La distinción entre «el mundo de los hechos» con la «objetividad operativa de los medios» y «el mundo de los fines», «el mundo de los valores», que queda al margen de la racionalidad, obliga a Weber a cuestionar la «objetividad» del sociólogo, producto también de una sociedad y una cultura con sus valores propios, de modo que la anhelada «objetividad» sólo se alcanza con una «ciencia social libre de valores». Reacción consecuente a la posición que había mantenido en su primera fase de economista, en la que, partiendo de un acérrimo nacionalismo, Weber había propugnado una «ciencia económica alemana».

En su ensayo de ruptura, La ética protestante y el espíritu del capitalis$m o$, además de cuestionar la posición del sociólogo, en cuanto inmerso en una cultura y en una clase social con sus valoraciones propias, Weber plantea un asunto de mucho mayor calado, ¿cómo construir un saber objetivo, que fun- 
damente una ciencia social, si lo racional tiene una multitud de significados? Racional quiere decir una óptima adecuación de los medios disponibles al fin que se pretende, pero este fin puede ser muy diverso y no cabe una discusión racional sobre los fines. Lo que caracteriza a nuestras sociedades es la pluralidad de los sistemas valorativos. Frente al «monoteísmo» ilustrado de la razón, es preciso convivir con el «politeísmo» que implica esta nueva comprensión de lo racional.

Esencial para el ulterior desarrollo de la sociología ha sido también el reconocimiento de la subjetividad que implica la argumentación weberiana. Los individuos tienen creencias que responden a su propia lógica interna, factor irreductible, aunque «emparentado», es decir, en «relación de parentesco» con las estructuras socioeconómicas. En consecuencia, no se puede hacer ciencia social eliminando la subjetividad, como si se tratase de un factor distorsionante, error en el que cayó el marxismo de la segunda internacional y recalcó aún más el de la tercera.

Max Weber fue catedrático de economía en Friburgo y Heidelberg, y hasta terminada la Gran Guerra, no ocupó la primera cátedra de sociología en Múnich poco antes de morir en 1920, a los 56 años. Lo que mejor pone de manifiesto la irrelevancia, y consiguiente desconexión de la sociología europea en este «segundo nacimiento» a finales del siglo XIX, es que Durkheim y Weber, pese a ser coetáneos —Durkheim era sólo 6 años mayor que Weber-, nada supiera el uno del otro. Los europeos nos enteramos de la importancia de ambos por el libro de Parsons. Gracias a la influencia norteamericana y dentro de la discusión de una ciencia social «objetiva, libre de valoraciones subjetivas», Max Weber logra reconocimiento como sociólogo en los años 50. En Europa la sociología se institucionaliza, después de la II Guerra Mundial, y por influencia directa de Estados Unidos, la nueva potencia hegemónica de la Europa occidental. El enfrentamiento de la sociología con el marxismo en los años 50, 60 y 70 del siglo pasado constituye una peripecia más de la «guerra fría», sin la que no se entiende la sociología y el marxismo de aquellos decenios.

\section{Relato personal}

Debió ser en 1963 cuando René König invitó a Talcott Parsons a dar unas conferencias en la universidad de Colonia, y recuerdo con qué interés y enorme emoción le escuchábamos, aunque la claridad no fuese su fuerte. De aquel cursillo saqué en conclusión que había que estudiar las fuentes europeas, Durkheim y Weber - lamentablemente, asediado por mis prejuicios, no incluí a Pareto- y sobre todo que no debía dejarme encandilar por una construcción teórica como la parsoniana, que en cada libro que publicaba se hacía más compleja y cuestionable. De alguna forma sospechaba que la sociología 
norteamericana nos parecía importante, porque sin duda lo eran Estados Unidos - la hegemonía económica, social y política conlleva una cultural - aunque en la segunda posguerra tan sólo nos ofreciese aquello que había aprendido de Europa.

Enzarzados en una discusión metodológica con la filosofía y las diferentes ciencias sociales, sin embargo, la preeminencia de la sociología norteamericana era un axioma incontrovertible, y no sólo entre los sociólogos. Limitada a Alemania y simplificada al máximo, la polémica que dividía entonces a la sociología cabría resumirse en el enfrentamiento de los «dialécticos» de la escuela de Francfort con los «neopositivistas» de Colonia. Mientras los primeros se movían en el ámbito de un marxismo renovado, los segundos habían hecho suya la filosofía analítica del "círculo de Viena», que refugiada en Estados Unidos tras la anexión nazi de Austria, en los años 50 y 60 regresó a Europa con una fuerte impronta norteamericana.

Los representantes más conspicuos de esta tendencia en Colonia fueron Hans Albert, un privatdozent de «política social», y un joven sociólogo, ayudante de Ernst Topitsch, Gert Degenkolbe, buen amigo mío, con el que mantuve larguísimas discusiones, y que murió muy joven, en un desgraciadísimo accidente de coche. Gert había escapado de la Alemania oriental poco antes de la construcción del muro de Berlín en 1961 y soportaba mis simpatías por el socialismo, como propias de un español subdesarrollado, incapaz de desprenderse de las ligaduras del idealismo alemán, sobre todo, del más pernicioso, el de Hegel. Atribuía a mi procedencia el que no pudiese apreciar la evidencia clarificadora de la filosofía analítica, así como los bienes que aportaría una «ingeniería social», basada en la sociología proveniente de Estados Unidos. Si a mí me toleraba por exótico, en cambio, le sacaba de quicio que esta incapacidad la compartiese la gente de Francfort, sobre todo una joven figura en rápido ascenso, Jürgen Habermas, que se consideraba incluso marxista, aunque de un marxismo que nada tenía que ver con el soviético.

La «desviación» filosófica, que queda patente en el interés que en mí despertaron el idealismo hegeliano y el compromiso político que había adquirido en España, y que suele exacerbarse en el exilio, junto con el ambiente intelectual de la universidad alemana de aquellos años, explican el que de la sociología saltase muy pronto a un marxismo centrado en el joven Marx, dándole vueltas al concepto de «enajenación», que permitía una reinterpretación de la obra posterior que poco tenía que ver con el «materialismo dialéctico» que predicaban los soviéticos.

La lectura de Marx fue el acontecimiento decisivo de la segunda parte de los 60 , que viví junto con una buena parte de la juventud académica alemana. Este redescubrimiento de Marx no sólo ha marcado a toda mi generación, sino que define una relación nueva con la sociología que, más o menos subterránea, permanece indeleble hasta nuestros días. Cierto, con la «guerra fría» ha terminado el litigio marxismo-sociología que arrastrábamos desde la se- 
gunda mitad del XIX. Liberado por fin de la instrumentalización ideológica a la que lo había sometido el «totalitarismo estatalista», Marx ha renacido en estos últimos años - muy significativamente en primer lugar en Estados Unidos - no ya como el profeta de una sociedad sin clases, sino como un teórico imprescindible de la ciencia social. Es una noticia que tal vez aún no haya llegado a una buena parte de los científicos sociales, pero que cabe anunciar para un futuro próximo.

\section{La crisis de la sociología}

A partir de los 90, terminada la «guerra fría», cayó bruscamente la posición preponderante que la sociología había tenido en la segunda mitad del siglo XX. En los años 60, que muy bien cabría calificar como «la edad de oro de la sociología», se crearon muchas cátedras —en Alemania se pasó de 25 a 69 - y se introdujeron por doquier diplomaturas y licenciaturas en los planes de estudio. Además de sentirse orgullosa del grado de teorización alcanzado con figuras de relevancia mundial, como Talcott Parsons, Robert K. Merton, o Georg Caspar Homans, que parecían presagiar el que por fin se consolidase un paradigma teórico de amplio consenso, la sociología logra por fin establecerse como una profesión a la que se por descontado una demanda social creciente. La crisis actual se manifiesta, no sólo por haber perdido el prestigio académico de que gozó la sociología en aquellos años, sino sobre todo por no haber logrado asentarse como una profesión que ofreciese los puestos de trabajo esperados. También en este campo la sociología ha sucumbido ante la nueva ciencia social dominante, la economía, que además de haber conseguido un mayor grado de formalización teórica, prepara profesionales de los que sí hay una gran demanda.

La crisis de la sociología se evidencia en el hecho de que no haya conseguido un fundamento teórico compartido por la comunidad científica. Todo lo contrario, en lo que se refiere a conceptos básicos, perspectivas teóricas, métodos aplicables y evaluación de los resultados, cada vez se aleja más de un canon común. El disenso que ya había prevalecido a lo largo de más de dos siglos incluso ha aumentado, de modo que la sociología es hoy un conglomerado «multiparadigmático», en el que coexisten los paradigmas más diversos, incluso contradictorios, en vez de sucederse los unos a los otros, como ocurre en las ciencias naturales ${ }^{24}$. La mayor fractura se muestra entre los que aspiran a una visión global de la sociedad, y especulan sobre la «sociedad postindustrial», «la sociedad de la información», «la sociedad de ries-

24 Andreas Balog y Johann August Schülein, editores, Soziologie, eine multiparadigmatische Wissenschaft. Erkenntnisnotwendigkeit oder Übergangsstadium?, VS Verlag für Sozialwissenschaften, Wiesbaden, 2008. 
go» y un largo etcétera de denominaciones, y aquellos sociólogos que rechazan planteamientos globales especulativos y tratan de incluir los hechos recogidos en teorías de alcance medio. Mientras estos últimos, fieles a las fronteras establecidas, se empeñan en mantener la autonomía de la disciplina, los primeros para dar cuenta de las sociedades contemporáneas vuelven a la vieja pretensión de incluir todas las ciencias sociales, desde la historia a la economía, en una sola ciencia social que siguen llamando sociología.

En dos siglos la sociología no ha podido librarse de un dogmatismo objetivista - la realidad social estaría estructurada y el conocimiento captaría estas estructuras realmente existentes - ni de un empirismo radical, incapaz de orientarse en la «diversidad infinita» de lo fáctico, sin criterios para ordenar los datos empíricos que se amontonan, desconectados de cualquier enfoque valorativo. Los primeros tienden a generalizar su perspectiva valorativa, como si fuesen estructuras objetivas, los segundos son incapaces de elaborar los datos con conceptos que pongan orden en la «diversidad infinita» de lo real.

Una ciencia social que trate de explicar el comportamiento humano tiene que escapar a estos dos peligros, de una parte, ha de superar cualquier tentación de construir, hipostasiándolos, grandes sujetos, como «sociedad», «nación», «clase», operación que al final desemboca en una filosofía de la historia, harto cuestionable. Lejos de las grandes personificaciones, ha de identificar lo social con el tejido de acciones individuales que se entrelazan unas con otras, influyéndose mutuamente. Empero, cuando la sociología se desprende de la ambición de estudiar la evolución de las sociedades en su conjunto, y se reduce a enfocar el individuo en la multiplicidad de relaciones con los demás, corre el peligro de perderse por una multitud de hechos que no cabe integrar en teorías aceptadas por toda la comunidad científica. Las publicaciones sociológicas, o bien caen en el ensayismo especulativo, o bien, al quedar acotadas a una pequeña parcela empírica, resultan irrelevantes. Este fracaso suele enmascararse, diferenciando ámbitos propios para cada una de las ciencias sociales, y dentro de la sociología, una amplia gama de especializaciones: sociología urbana, sociología de la familia, sociología del conocimiento, estructura social y conflicto, y un larguísimo etcétera. Al subrayar la autonomía de cada ciencia social, y dentro de la sociología, la de sus muchas ramas, se facilita el poder declararse incompetente para entrar en cualquier problema acuciante que incida sobre intereses establecidos. Una buena parte de las cuestiones que de verdad importan quedan así fuera del alcance del sociólogo.

Pese a los muchos intentos desde el último tercio del siglo XIX en separar nítidamente las ciencias sociales de las ciencias naturales, el hecho es que hemos vuelto a los orígenes dieciochescos en el estudio conjunto del hombre en sus múltiples dimensiones, corporales, psíquicas y sociales. La que, como compendio de las diversas ciencias sociales, se llamó sociología tuvo su ante- 
cedente inmediato en una ciencia médica del hombre que niega el «espíritu», como una sustancia única y privativa de lo humano. «Todas las facultades del alma dependen de la organización propia del cerebro» ${ }^{25}$, órgano que comparte con los demás mamíferos superiores que, si no es igual, es bastante similar, y en consecuencia, «el hombre sólo es un animal» ${ }^{26}$, que forma parte de la naturaleza, como cualquier otro ser viviente.

El haber sido el hombre reintegrado a la naturaleza, sin que haya que reconocerle un status especial — no se distingue de manera sustancial de los otros seres vivientes - ha posibilitado, tanto el desarrollo de la medicina moderna, como el de las ciencias sociales. Los enormes avances en la genética y en la neurociencia de los últimos decenios han revalidado la idea ilustrada de que el hombre, en cuanto parte de la naturaleza, sólo se entiende en el contexto y con los mismos procedimientos de las ciencias naturales. En los años 40 y 50 del siglo pasado, el positivismo renovado en el «positivismo lógico» volvió a plantear la unidad de las ciencias, un empeño que se ha ido fortaleciendo con los años y que nos devuelve a las posiciones originarias de la sociología en las que se defendía la unidad constitutiva de las ciencias sociales y naturales. La crisis actual de la sociología ofrece la oportunidad de volver a una ciencia integral del hombre a la que Saint-Simon llamó «fisiología». En un momento en el que las ciencias sociales están a la expectativa de los grandes descubrimientos que se han realizado, y sobre todo los que se esperan en breve del estudio del cerebro, se puede afirmar que la neurociencia se ha convertido en el verdadero fundamento de una ciencia del hombre, tal como aquella a que aspiró la sociología en su primera fase fundacional.

25 Es la tesis central del médico Julien Offray de La Mettrie, L'Homme Machine (1748), Georg Olms Verlag, Hildesheim, 1988, p. 330.

26 Idem, p. 339. 